\title{
Targeted inactivation of nuclear interaction partner of ALK disrupts meiotic prophase
}

\author{
Anna Lena Illert ${ }^{1}$, Hiroyuki Kawaguchi ${ }^{2, *, *}$, Cristina Antinozzi ${ }^{3, \pm}$, Florian Bassermann ${ }^{1}$, \\ Letitia Quintanilla-Martinez ${ }^{4}$, Christine von Klitzing ${ }^{1}$, Mitsuteru Hiwatari ${ }^{2}$, Christian Peschel ${ }^{1}$, \\ Dirk G. de Rooij ${ }^{5}$, Stephan W. Morris ${ }^{2}$, Marco Barchi ${ }^{3}$ and Justus Duyster ${ }^{1, \S}$
}

\begin{abstract}
SUMMARY
NIPA (nuclear interaction partner of ALK) is an F-box-like protein that monitors the timing of mitotic entry. Constitutively active NIPA delays mitotic entry by preventing accumulation of nuclear cyclin B1. Here, we have investigated the consequences of Nipa inactivation by using a conditional knockout strategy. Nipa-deficient animals are viable but show a lower birth rate and reduced body weight. Furthermore, Nipa-deficient males are sterile owing to a block of spermatogenesis during meiotic prophase. Whereas $\mathrm{Nipa}^{-/-}$mouse embryonic fibroblasts show no severe phenotype, Nipa ${ }^{-/}$spermatocytes arrest during stage IV of the epithelial cycle with subsequent TUNEL-positive apoptosis resulting from improper synapsis, defects in the repair of DNA double-stranded breaks and synaptonemal complex formation. Moreover, we show nuclear accumulation of cyclin B1 with a subsequent premature increase in $\mathrm{G}_{2} / \mathrm{M}$ kinase activity in $\mathrm{Nipa}^{-/-}$spermatocytes. Together, these results reveal a novel role for NIPA in meiosis.
\end{abstract}

KEY WORDS: Cell cycle, Knockout mouse, Meiosis, NIPA (ZC3HC1), CCNB1, Checkpoint

\section{INTRODUCTION}

The regulated oscillation of protein expression and degradation is an essential mechanism of cell cycle control (Hochstrasser, 1996). F-box proteins (FBPs) play a crucial role in the ubiquitin-mediated degradation of regulatory proteins, as they are substrate recognition subunits of SCF-type E3 ubiquitin ligases. These complexes consist of four subunits: S-phase kinase-associated protein 1 (SKP1), Cullin protein 1 (CUL1), RING-finger protein (ROC1) and the interchangeable FBP (Cardozo and Pagano, 2004). The core components of the SCF (SKP1, CUL1, ROC1; RBX1 - Mouse Genome Informatics) are abundant throughout the cell cycle and interact with the FBPs through their SKP1-binding domain (Cardozo and Pagano, 2004). The substrate specificity of SCF ligases is dictated by different FBPs that act as substrate-targeting subunits: therefore, large families of FBPs are present in all eukaryotes to ensure high specificity. In mammals more than 70 FBPs have been identified, yet only six have been linked to specific substrates [SKP2, $\beta$-TRCP (BTRC - Mouse Genome Informatics), NIPA, FBXL3, FBXO4, FBXW7 and FBXO31] (Santra et al., 2009; Skaar et al., 2009a; Skaar et al., 2009b). Gene knockout phenotypes have recently revealed several important functions of selected F-box proteins in vivo. For example, inactivation of $\beta$ TRCP leads to defective spermatogenesis, subtle mitotic defects and chromosome overduplication (Guardavaccaro et al., 2003).

\footnotetext{
${ }^{1}$ Department of Internal Medicine III, Technical University of Munich, Munich 81675, Germany. ${ }^{2}$ Departments of Pathology and Oncology, St Jude Children's Research Hospital, Memphis, TN 38105, USA. '3epartment of Biomedicine and Prevention, Section of Anatomy, University of Rome 'Tor Vergata', Rome 00133, Italy. ${ }^{4}$ Institute of Pathology, Eberhard-Karls-University of Tübingen, Tübingen 72076, Germany. ${ }^{5}$ Center for Reproductive Medicine, Academic Medical Center, University of Amsterdam, Amsterdam AZ 1105, The Netherlands.

*Present address: Department of Pediatrics, National Defense Medical College, Saitama 359-8513, Japan

${ }^{\ddagger}$ These authors contributed equally to this work

§Author for correspondence (justus.duyster@|rz.tum.de)
}

Targeting of the $S k p 2$ locus results in hypoplasia of most organs, centrosome overduplication and defects of mitotic entry (Nakayama et al., 2000), whereas the $F b x w 7$ knockout mouse has an embryonic lethal phenotype, probably owing to morphogenetic cardiovascular defects (Tetzlaff et al., 2004). Thus, with the exception of FBXW7, FBP knockout animals are viable despite the variety of FBP substrate proteins affected. Likewise, knockout studies have identified prominent cell cycle regulatory genes, such as $C d c 25 c$ or $C d k 2$, as non-essential genes (Berthet et al., 2003; Chen et al., 2001; Ortega et al., 2003). These observations highlight the possibility that cell cycle regulation in embryonic stem (ES) cells is different from that in differentiated or tumor cell lines.

We have previously reported the cloning of Nipa (nuclear interaction partner of ALK; Zc3hcl - Mouse Genome Informatics) in complex with constitutively active oncogenic fusion forms of ALK (anaplastic lymphoma kinase) (Ouyang et al., 2003), which contribute to the development of certain lymphomas, sarcomas and lung carcinomas (Li and Morris, 2008; Morris et al., 1994; Soda et al., 2007). We characterized NIPA as a mammalian F-boxcontaining protein that defines an SCF-type ubiquitin E3 ligase $\left(\mathrm{SCF}^{\mathrm{NIPA}}\right)$ (Bassermann et al., 2005b). Interestingly, the SCF ${ }^{\mathrm{NIPA}}$ complex displays oscillating activity, which is controlled by cell cycle-dependent inhibitory phosphorylation of NIPA in late $\mathrm{G}_{2}$ phase, resulting in NIPA dissociation from the SCF-core (Bassermann et al., 2007; Bassermann et al., 2005b). Cyclin B1 (CCNB1) was identified as a substrate, which is targeted by the $\mathrm{SCF}^{\mathrm{NIPA}}$ for ubiquitylation in interphase within the nuclear cell compartment (Bassermann et al., 2005b) (supplementary material Fig. S1).

Entry into mitosis is triggered by CCNB1/CDK1 (the M-phasepromoting factor or MPF). Nuclear abundance of CCNB1 is a major determinant of MPF activity, thus requiring regulatory machinery to time subcellular localization of CCNB1. In this regard, phosphorylation of the CRS (cytoplasmic retention signal) has been identified as a means to localize CCNB1 to the nucleus prior to mitosis (Pines and Hunter, 1991; Yang et al., 1998). The $\mathrm{SCF}^{\mathrm{NIPA}}$ complex degrades nuclear CCNB1 in interphase, thus 
providing a further safeguard mechanism to protect the cell from untimely nuclear CCNB1 accumulation (Bassermann et al., 2005b). The phosphorylation of NIPA at $\mathrm{G}_{2} / \mathrm{M}$ induces its release from the SCF core complex, leading in turn to an increase of nuclear CCNB1 levels required for the progression into mitosis. Consequently, our last studies demonstrated that expression of phosphorylation-deficient mutants of Nipa (constitutively active) results in a block in mitotic prophase owing to insufficient nuclear CCNB1 accumulation (Bassermann et al., 2007; Bassermann et al., 2005b).

We have now characterized the consequences of NIPA deficiency in vivo by targeting the Nipa locus by homologous recombination in ES cells and analyzed the effects on somatic cells and testicular germ cells (GCs). We were able to observe evidence for a new unexpected role of the $\mathrm{SCF}^{\mathrm{NIPA}}$ complex in the regulation of meiosis.

\section{MATERIALS AND METHODS \\ Generation of $\mathrm{Nipa}^{-/-}$mice}

The conditional knockout vector was generated using 'recombineering' strategy (Liu et al., 2003). Briefly, two 500 bp and four 200 bp fragments were amplified, larger fragments were ligated into vector pL253 for retrieval and smaller fragments into pL451 or pL452 for mini targeting. BAC clones were purchased from Invitrogen and the Nipa fragment was retrieved from one BAC clone by co-transfecting pL253/ABXY and BAC-DNA in the recombinogenic cell EL350. Vectors which obtained Nipa fragments were subjected to mini-targeting with pL452/CDEF2 to insert loxP site $5^{\prime}$ of the Nipa-promoter region. Thereafter, another minitargeting with $\mathrm{pL} 451 / \mathrm{GH} 2 \mathrm{I} 2 \mathrm{~J} 2$ integrated a Neo-gene-cassette flanked by two FRT sequences and a 3' downstream loxP site. After electroporation of the targeting vector into the ES cell line (CMT1; Specialty Media), selected $(300 \mu \mathrm{g} / \mathrm{ml} \mathrm{G} 418 ; 2 \mathrm{mM}$ ganciclovir) and correctly targeted clones were identified by PCR and Southern blotting. Neo-cassette was deleted by transfecting FLP recombinase expression vector pCAGGSFLPe (Gene Bridges). Two mutant ES cell clones were microinjected (C57BL/6 blastocysts) and resulting male chimeras were mated with female C57BL/6 mice. Heterozygous offspring was intercrossed to produce mutant animals: $\mathrm{Nipa}^{\mathrm{CKO} / \mathrm{CKO}}$. For deletion of Nipa, these animals were bred with an ubiquitously expressing CMV-Cre transgenic mouse strain (Rajewsky et al., 1996; Schwenk et al., 1995). All mice were maintained in animal facility at St Jude Children's Research Hospital (Memphis, TN, USA) and Technical University of Munich (Germany). All experiments were performed in at least eight-generation C57BL/6-backcrossed mice, unless otherwise stated. Mendelian ratio was calculated using mice with mixed background (SV129/C57BL76) and backcrossed C57BL/6 mice.

NIPA is a synonym for zinc-finger $\mathrm{C} 3 \mathrm{HC}$ type-containing 1 protein (ZC3HC1) with the NCBI RefSeq accession number NM_016478.3 (mRNA transcript) and NP_057562.3 (protein).

\section{Histology and immunohistochemistry}

For histology, tissues were dissected, fixed (4\% formalin) and paraffin embedded. Sections (3-5 $\mu \mathrm{m})$ were cut and stained with Hematoxylin and Eosin. Immunohistochemistry was performed on an automated immunostainer (Ventana Medical Systems, Tucson, AZ, USA, according to the manufacturer's protocol.

\section{Preparation of MEFs}

Primary MEFs were prepared from embryos on embryonic day (E) 13.5 and cultured as described previously (Hartmann et al., 2002).

\section{Plasmids and antibodies}

Details of the construction of plasmid pcDNA3.1-Flag-mNipa are available upon request. Mouse-monoclonal antibodies were purchased from Sigma [anti-FLAG (M2), anti- $\beta$-actin] and Santa Cruz [anti-CCNB1 (GNS-1), anti- $\alpha$-tubulin]. Polyclonal rabbit antibodies were from Santa Cruz [antiCCNA2, anti-WEE1, anti-CDC25B, anti-CCNB1 (H-433), anti-Dmc1],
Cell Signaling [anti-phospho-CDC2 (Tyr15), anti-CDC2, anti-caspase 3, anti-cleaved-caspase 3, anti-PLK1, anti-MAPKp42/p44], R\&D (antisurvivin), Novus (anti-SYCP1) and Upstate (anti-phospho-H3). Polyclonalrabbit antibody against H1t was a gift from P. Moens (York University, UK) (Moens et al., 1997); against STAG3 from R. Jessberger (Technical University of Dresden, Germany); against SYCP3 from P. Cohen (Cornell University College of Veterinary Medicine, USA); and against TRF1 from T. De Lange (Rockefeller University, USA). A peptide (LDFHADDRKTTSK) was used to raise polyclonal-antibodies against murine NIPA in rabbits. Human NIPA was detected as previously described (Bassermann et al., 2005a; Bassermann et al., 2007).

\section{Transient transfection and siRNA}

Transient transfections were performed using Lipofectamine 2000 (Invitrogen). siRNAs were used as previously described (Bassermann et al., 2005b).

\section{Isolation, cell culture and treatments of germ cells}

Testicular GC suspension were isolated and cultured following the methods described by Jeyaraj et al. (Jeyaraj et al., 2002) and Sette et al. (Sette et al., 1999). Isolated cells were either fixed ( $70 \%$ cold methanol) or cultured overnight (MEM, $0.5 \%$ BSA, $1 \mathrm{mM}$ sodium pyruvate and $2 \mathrm{mM}$ sodium lactate; $32^{\circ} \mathrm{C}$ ). After 12 hours, cells were treated with $5 \mu \mathrm{M} \mathrm{OA}$, and culture was continued up to 5 hours. For time course experiments, aliquots were taken and processed as described below. For cytological analysis and kinase assays, aliquots were taken and processed accordingly.

\section{Flow cytometry analysis of germinal cells}

Ethanol-fixed GCs $\left(1 \times 10^{6}-2 \times 10^{6}\right)$ were washed twice (PBS) and incubated in $500 \mu \mathrm{l}$ of $0.2 \%$ pepsin $\left(10\right.$ minutes at $\left.36^{\circ} \mathrm{C}\right)$. After centrifugation, cells were stained with $25 \mu \mathrm{g} / \mathrm{ml} \mathrm{PI}, 40 \mu \mathrm{g} / \mathrm{ml}$ RNase and $0.3 \%$ Tween- 20 in PBS (room temperature for 30 minutes). For TUNEL labeling, $2 \times 10^{6} \mathrm{GCs}$ were washed, treated with pepsin and TdT-mediated dUTP-biotin nick end labeling was performed using the APO-Direct Kit (BD Biosciences).

\section{H1-kinase assay}

Cells $\left(2 \times 10^{5}\right)$ were collected in $10 \mu 1$ of storage solution $(10 \mathrm{mM} p$ nitrophenyl phosphate, $20 \mathrm{mM} \beta$-glycerolphosphate, $0.1 \mathrm{mM}$ sodium orthovanadate, $5 \mathrm{mM} \mathrm{EGTA}, 10 \mu \mathrm{g} / \mathrm{ml}$ leupeptin and $10 \mu \mathrm{g} / \mathrm{ml}$ aprotinin), then immediately frozen $\left(-80^{\circ} \mathrm{C}\right)$. Cells were thawed, lysed for 10 minutes in $50 \mu$ l hypotonic $\mathrm{H} 1$ kinase buffer [ $25 \mathrm{mM}$ MOPS ( $\mathrm{pH} 7.5), 60 \mathrm{mM} \beta$ glycerolphosphate, $15 \mathrm{mM}$ EGTA, $15 \mathrm{mM} \mathrm{MgCl}_{2}, 0.1 \mathrm{mM}$ sodium orthovanadate, $1 \mathrm{mM}$ DTT, $10 \mu \mathrm{g} / \mathrm{ml}$ leupeptin and $10 \mu \mathrm{g} / \mathrm{ml}$ aprotinin], centrifuged for 10 minutes $\left(10,000 \mathrm{~g}\right.$ at $\left.4^{\circ} \mathrm{C}\right)$ and soluble extracts were collected. Kinase reactions using 10-15 $\mu$ l of extracts were carried out for 60 minutes at $30^{\circ} \mathrm{C}$ in a total volume of $25 \mu \mathrm{l}$ in $\mathrm{H} 1$ kinase-buffer containing $100 \mu \mathrm{g} / \mathrm{ml} \mathrm{H1}$ (type III-S; Sigma), $1 \mu \mathrm{g} / \mathrm{ml}$ cAMP-dependent protein kinase inhibitor (Sigma), and $1 \mu \mathrm{Ci}\left[\gamma^{32} \mathrm{P}\right]$ ATP (Amersham). Additional aliquots were collected for protein measurement by BIO-RAD DC Protein Assay (Lowry et al., 1951). Input of lysates into kinase assay was thereby calculated.

\section{Chromosome spreads of spermatocytes}

Testis cell preparation were prepared for surface spreading as described previously from 16 dpp mice unless otherwise stated (Barchi et al., 2009; Barchi et al., 2005). An indirect immunofluorescence analysis of spread chromosomes was performed using described methods and antibodies (Barchi et al., 2005)

\section{Immunoprecipitation and immunoblot analysis}

Immunoprecipitations and immunoblot analysis were performed as described previously (Ouyang et al., 2003).

\section{RESULTS}

\section{Phenotypic analysis of NIPA knockout mice}

To generate Nipa-deficient mice, we introduced two loxP sites into the Nipa locus by homologous recombination in ES cells (Fig. 1A). Removal of these sequences by CRE recombinase eliminated the 

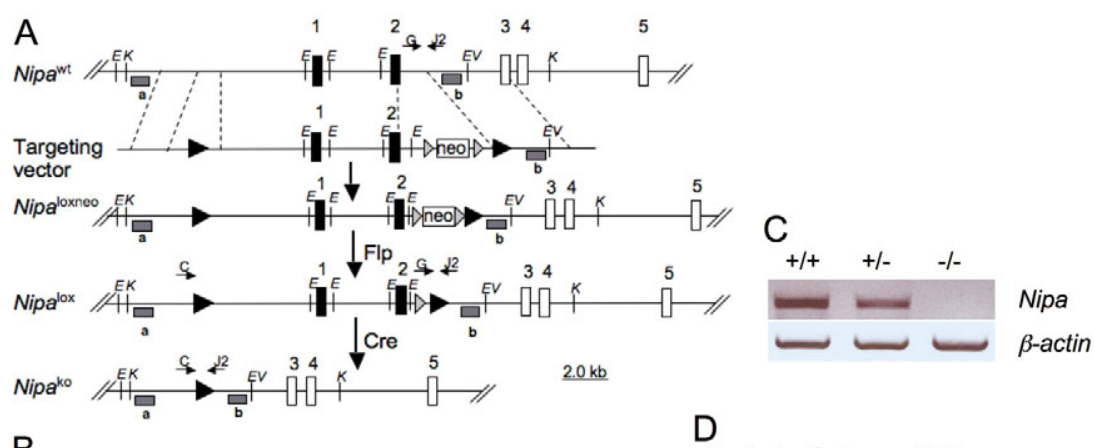

B

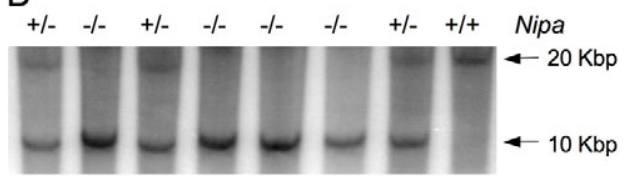

D

Testicular Cells MEFs

$+1++1-t-1-t+1+$

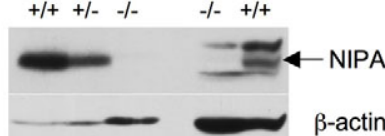

E

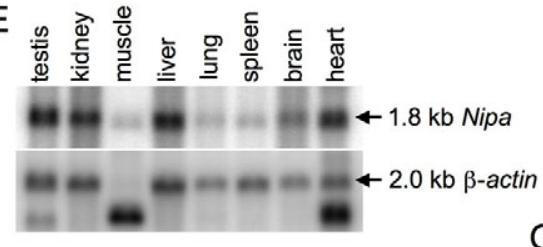

$\mathrm{F}$

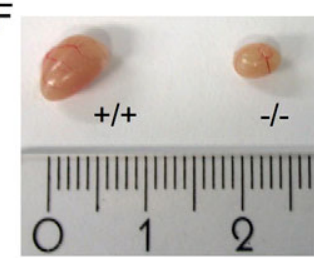

E7 E11 E15 E17

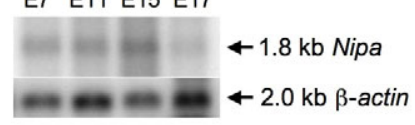

G 160

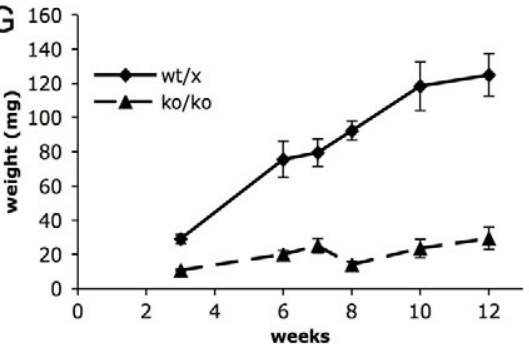

Fig. 1. Generation of mice lacking NIPA and phenotypic analysis of $\mathrm{Nipa}^{-/-}$mice. (A) Nipa alleles. The mouse Nipa locus contains 10 exons spanning $25 \mathrm{~kb}$. Coding sequences (boxes), nontargeted coding sequences (white boxes), targeted exons (black boxes), loxP sites (black triangles) and Flp sites (gray triangles) are indicated. neo, PGK$n{ }^{r}$ cassette; Cre, bacteriophage Cre recombinase; Flp, Saccharomyces cerevisiae Flp recombinase; E, EcoRl; K, Kpnl; EV, EcoRV; a, 5' probe; b, 3' probe. Wild-type and mutated Nipa alleles are indicated. (B) Southern blot analysis of genomic DNA. After $K p n l$ digestion, hybridization with the $3^{\prime}$ probe $\mathrm{b}$ detects a $20 \mathrm{~kb}$ wild-type and a $10 \mathrm{~kb}$ mutant Nipa DNA fragment. (C,D) Level of Nipa transcripts (C) and NIPA protein (D). Total RNAs were prepared from MEFs and processed for RT-PCR using exon primers for full-length Nipa and $\beta$-actin (C). Lysates from testicular cells and MEFs were subjected to immunoblotting (D). $\beta$-Actin served as loading control. (E) Nipa expression patterns in various adult organs (left panel) and during embryogenesis (right panel). Murine tissue and embryo mRNA blots were hybridized with a specific Nipa probe and reprobed with $\beta$-actin. (F) Testes from wildtype and $\mathrm{Nipa}^{-/-}$3-month-old mice. (G) Testicular weight at different ages (wt/x, $n=40 ; \mathrm{ko} / \mathrm{ko}, n=32$ ). Data are mean \pm s.e.m. first two exons of Nipa. Correct targeting was confirmed by Southern blot analysis (Fig. 1B) and PCR (supplementary material Fig. S2). Full ORF of the Nipa cDNA could be amplified from wild-type but not from $\mathrm{Nipa}^{-/-}$mouse embryonic fibroblasts (MEFs) (Fig. 1C). Western blot analysis confirmed that NIPA protein was absent in both $\mathrm{Nipa}^{-/}$MEFs and testicular cells (Fig. 1D). Notably, testicular cells demonstrated elevated expression levels when compared with MEFs. Despite widespread expression in somatic tissues and during embryogenesis (Fig. 1E), $\mathrm{Nipa}^{-/}$ mice were viable and the frequency corresponded to reduced Mendelian ratio $\left(\mathrm{Nipa}^{-/-}\right.$16.36\%, $\mathrm{Nipa}^{+/-} 54.03 \%, \mathrm{Nipa}^{+/+} 29.60 \%$; $n=1736)$ with a normal male: female ratio (51.7\% versus $48.3 \%$; $n=282$ ). Further analysis of NIPA expression by immunostaining of wild-type embryos demonstrated high abundance of NIPA restricted to the actively dividing cell compartment in testis, intestine, skin and kidney (supplementary material Fig. S3). Interestingly, $\mathrm{Nipa}^{-/-}$mice were found to be smaller than control animals with the difference being more pronounced in males (supplementary material Fig. S4). Otherwise, Nipa ${ }^{-/}$animals developed normally, and anatomical and histological examination of the mutant mice revealed no obvious malformations with the exception of the gonads (Fig. 1F,G). Multiple breeding experiments indicated complete infertility of $\mathrm{Nipa}^{-/-}$males and reduced fertility of females (Table 1).

\section{NIPA is essential for progression through prophase of meiosis I}

$\mathrm{Nipa}^{-/-}$males showed progressive atrophy of the gonads (Fig. 1G; supplementary material Fig. S5) starting before sexual maturity. Reduction of testis weight in $\mathrm{Nipa}^{-/-}$animals was already evident in three-week-old pups. In male mice, spermatogonial stem cells are located at the periphery of the seminiferous tubule. These cells undergo several mitotic divisions before giving rise to spermatocytes, where meiosis takes place. In immunohistological analyses, we observed an overall reduction of seminiferous tubule diameter resulting from depletion of all germinal cells, which

Table 1. Fertility of wild-type and Nipa mutant mice

\begin{tabular}{lcccc}
\hline & Genotype & Fraction fertile (fertile/total) & Litters/fertile pair & Mean litter size $(n)$ \\
\hline Female & Nipa & 4.3 & 7.9 \\
& $\mathrm{Nipa}^{+/-}$ & $10 / 5$ & 4.2 & 8.1 \\
& $\mathrm{Nipa}^{-/-}$ & $4 / 10$ & 2.3 & 3.3 \\
\hline Male & $\mathrm{Nipa}^{+/+}$ & $5 / 5$ & 4.3 & 7.9 \\
& $\mathrm{Nipa}^{+/-}$ & $10 / 10$ & 4.2 & 8.1 \\
& $\mathrm{Nipa}^{-/-}$ & $0 / 10$ & 0 & 0 \\
\hline
\end{tabular}

Males and females (8-12 weeks of age) of the three different genotypes were tested for fertility for a period of $\sim 3$ months with young wild-type males and females. Copulatory behavior was judged to be normal and vaginal plugs were regulary found. Sixty percent of Nipa ${ }^{-1}$ females were sterile and the remaining $40 \%$ had reduced fertility, when judged by the number of litters generated and the mean litter size. All of the tested Nipa ${ }^{-/}$males were sterile. 


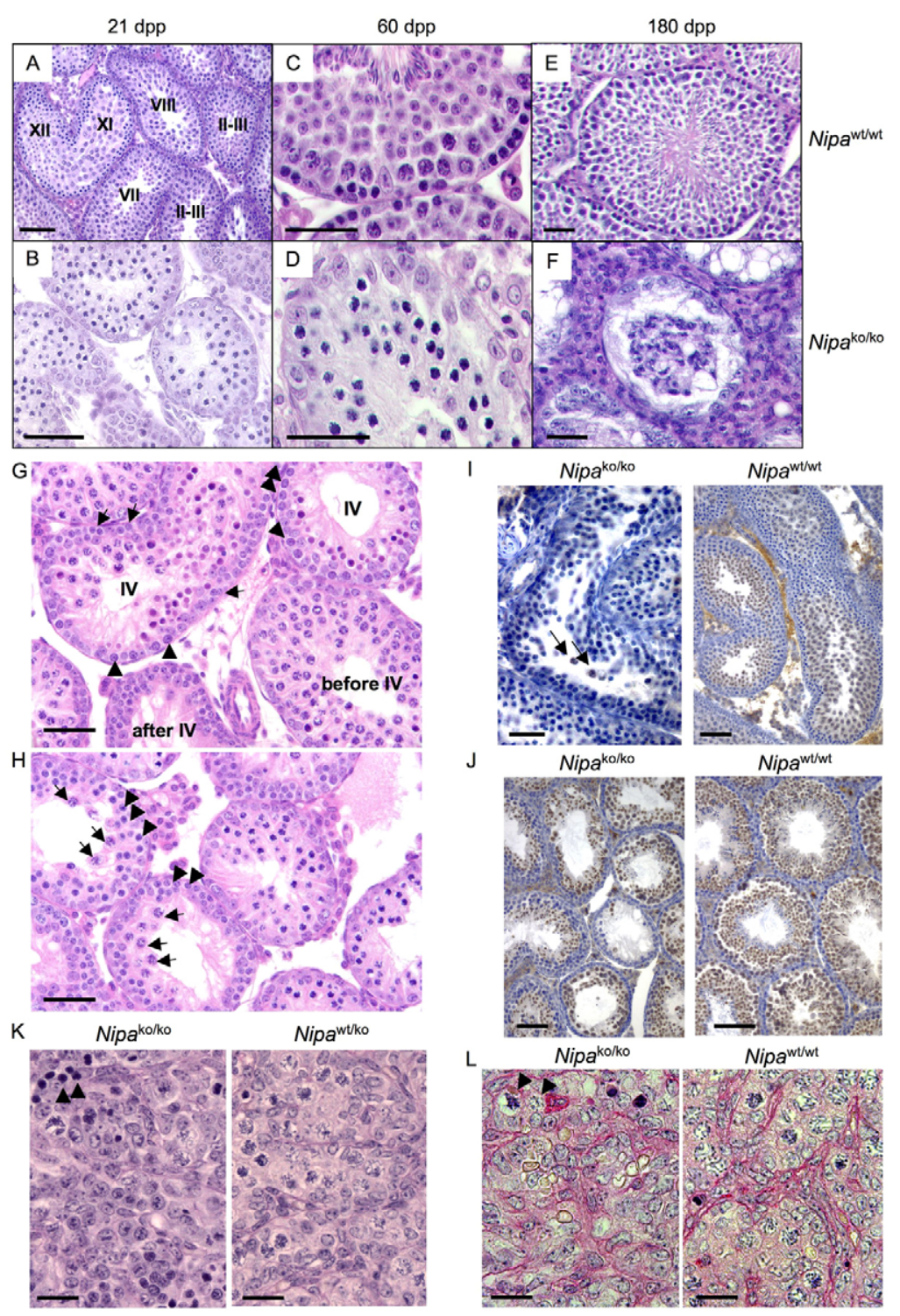

Fig. 2. $\mathrm{Nipa}^{-/-}$mice display a delay in meiotic progression. (A-F) Histological analyses of $21 \mathrm{dpp}(\mathrm{A}, \mathrm{B}), 60$ $\mathrm{dpp}(\mathrm{C}, \mathrm{D})$ and $180 \mathrm{dpp}(\mathrm{E}, \mathrm{F})$ testes obtained from $\mathrm{Nipa}^{+/+}$ and $\mathrm{Nipa}^{-/-}$mice. (G) Stage IV arrest of $\mathrm{Nipa}^{-/-}$mice (20 $\mathrm{dpp})$, characterized by intermediate spermatogonia (arrowheads) about to divide or just divided into Typ B spermatogonia (arrows). In tubules after stage IV, all older spermatocytes disappeared. (H) Nipa ${ }^{-/-}$tubules (20 dpp) in stages after IV showing preleptotene (arrowheads) spermatocytes and few older stages (arrows) that survived stage IV but enter apoptosis later on without reaching meiotic divisions. (IJJ) $\mathrm{H} 1 \mathrm{t}$ immunostaining in the seminiferous tubules of $21 \mathrm{dpp}(\mathrm{I})$ and $90 \mathrm{dpp}(\mathrm{J})$ testes. (K) Ovaries isolated from E13.5-E14.5 littermates showing apoptosis (arrowheads) in early meiotic prophase of $\mathrm{Nipa}^{-1-}$ oocytes. (L) Ovaries isolated at E18.5 showing many oocytes in wild-type ovaries, whereas in $\mathrm{Nipa}^{-/}$ovaries, only a few oocytes (arrowheads) are left. Scale bars: $100 \mu \mathrm{m}$ in $A, B, I$ (right panel), J; $40 \mu \mathrm{m}$ in $\mathrm{C}-\mathrm{H}, \mathrm{I}$ (left panel); $10 \mu \mathrm{m}$ in $\mathrm{K} ; 5 \mu \mathrm{m}$ in $\mathrm{L}$. became more profound in older animals. Representative tubules from $21 \mathrm{dpp}$ (days post partum), $60 \mathrm{dpp}$ and $180 \mathrm{dpp} \mathrm{Nipa}^{-/-}$and control mice are shown in Fig. 2A-F. At $21 \mathrm{dpp}$, when many of the spermatocytes are expected to have reached and passed the pachytene stage, abundant numbers of spermatogonial stem cells and spermatocytes were visible in tubules of wild-type mice. At 60 dpp, spermiogenesis is completed and mature sperms can be seen. By contrast, $\mathrm{Nipa}^{-/}$mice showed reduced tubule diameter (Fig. 2B) as result of reduced cellularity. However, although spermatogonia appeared to present in a roughly normal number, spermatocytes content was obviously reduced and neither metaphase I/metaphase II cells nor round spermatids or sperms were seen (Fig. 2B,D). At 180 dpp (Fig. 2E,F), we observed entirely empty tubules in $\mathrm{Nipa}^{-/-}$males, without residual spermatogonia, thus suggesting a potential mitotic proliferation defect of $\mathrm{Nipa}^{-/-} \mathrm{GCs}$.

Detailed analyses revealed that $\mathrm{Nipa}^{-/-}$spermatogenesis was mostly arrested at stage IV of the epithelial cell cycle by massive apoptosis of virtually all spermatocytes (Fig. 2G). However, some spermatocytes occasionally escaped this arrest, as judged by the presence of some post-meiotic cells, but these cells gradually disappeared as they entered apoptosis at later stages, implying that cells that escape pachytene arrest could not complete spermatogenesis (Fig. 2H). In histological analyses up until $47 \mathrm{dpp}$, no spermatocytes reached meiotic divisions and round spermatids were not seen. This observation was confirmed by immunofluorescent staining of chromosome spreads for the midpachynema-specific marker histone 1t (H1t). At 16 dpp, H1t-positive cells were seen in control but not in $\mathrm{Nipa}^{-/}$testis (supplementary material Fig. S6). At $21 \mathrm{dpp}, \mathrm{Nipa}^{-/-}$testis showed exceptionally $\mathrm{H} 1 \mathrm{t}-$ positive cells (arrows in Fig. 2I). Staining of $\mathrm{Nipa}^{-/-}$testis with a M-specific marker (phospho-Histone-3) revealed that, at $55 \mathrm{dpp}$, diplotene MI and MII cells are nearly absent compared with wildtype animals (supplementary material Fig. S7). However, midpachynema H1t-positive cells were visible in some $\mathrm{Nipa}^{-/}$testes at $90 \mathrm{dpp}$, as well as few round and elongated spermatids (Fig. 2J).

Immunostaining with a NIPA-specific antibody revealed highest expression of NIPA in pachytene spermatocytes and weaker staining in the post-meiotic compartment (supplementary material Fig. S8). The developmental arrest of $\mathrm{Nipa}^{-/}$spermatocytes resulted in the complete absence of spermatozoa in the tubule lumens and in the epididymis (supplementary material Fig. S9). 
Fertility of females was also affected by deletion of Nipa. Female GCs complete early stages of meiotic prophase I during fetal development and undergo cell cycle arrest around birth. After birth, each surviving oocyte becomes surrounded by somatic cells, forming a primordial follicle that remains arrested until recruited for further development during the reproductive life (van den Hurk and Zhao, 2005). Ovaries of $\mathrm{Nipa}^{-/-}$animals showed mostly complete absence of primordial follicles and corpora lutea. Instead, cysts lined with a layer of epithelial cells replaced the ovarian tissue (supplementary material Fig. S10). The absence of primordial follicle development in $\mathrm{Nipa}^{-/-}$females was a consequence of failure during embryogenesis. Analyses of embryonic ovaries displayed the loss of $\mathrm{Nipa}^{-/-}$oocytes during the course of prophase. $\mathrm{Nipa}^{-/-}$ovaries isolated by the beginning of meiotic prophase (E13.5-E14.5) showed extensive apoptosis in early prophase (Fig. 2K; supplementary material Fig. S11), whereas heterozygous littermates showed normal development of early prophase oocytes. As a consequence of massive oocyte loss, only very few oocytes are left at E18.5 in
$\mathrm{Nipa}^{-/-}$ovaries (Fig. 2L). By contrast, wild-type ovaries demonstrated many oocytes in late pachytene as judged from nuclei size and morphology of contracted chromosomes.

To further characterize the failure of meiotic progression in $\mathrm{Nipa}^{-/-}$animals, we isolated and quantified testis cell content. As expected from the histological analyses, we found a dramatic decrease in testicular cell number in $\mathrm{Nipa}^{-/-}$males (to $12 \%$ of that in wt/het) (Fig. 3A). Immediately before prophase, GCs duplicate their DNA content from $2 \mathrm{C}$ to $4 \mathrm{C}$. Through two meiotic divisions, haploid $1 \mathrm{C}$ cells are formed. We compared DNA content of enriched GCs from testis at different ages (Fig. 3B). Nipa $^{-1-}$ mice showed a distinct different DNA distribution compared with wildtype littermates. The first wave of spermatogenesis starts shortly after birth and GCs enter meiotic prophase at about $7 \mathrm{dpp}$, where the same distribution of testicular cells could be found in knockout and wild-type mice (with slightly increased 4C cell population of $\mathrm{Nipa}^{-/-}$males). Two weeks later, cells that have passed the first and second meiotic division were observed with a haploid chromosome

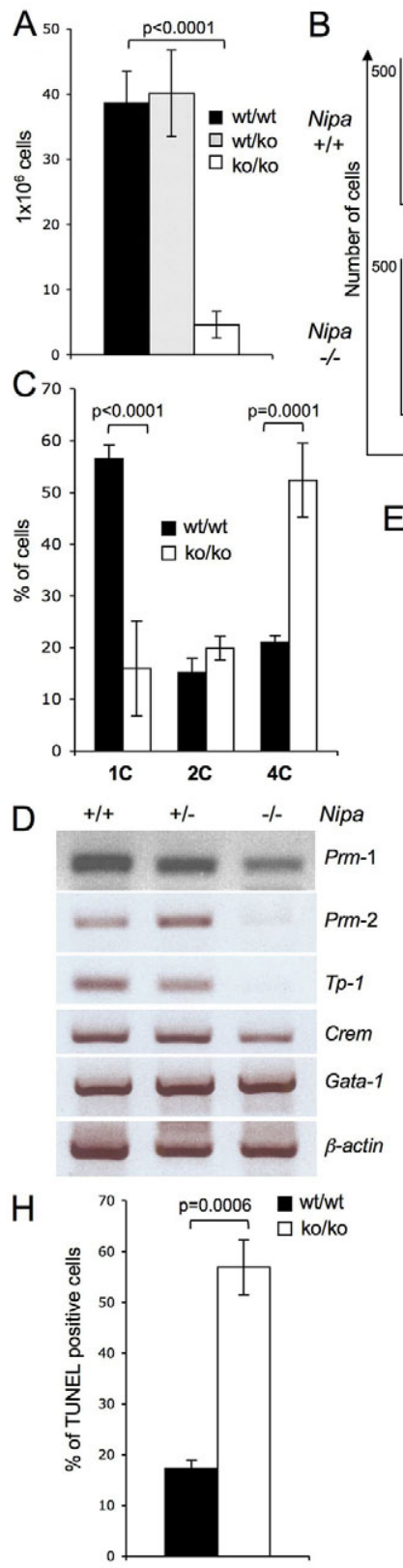

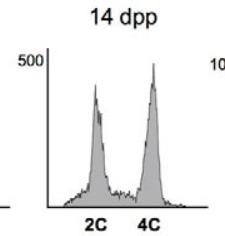
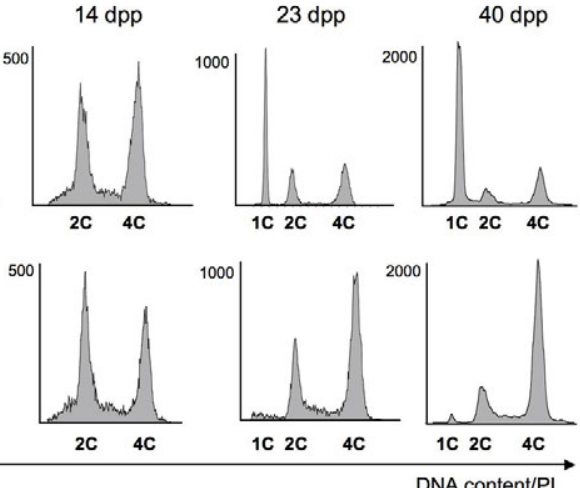

$E$
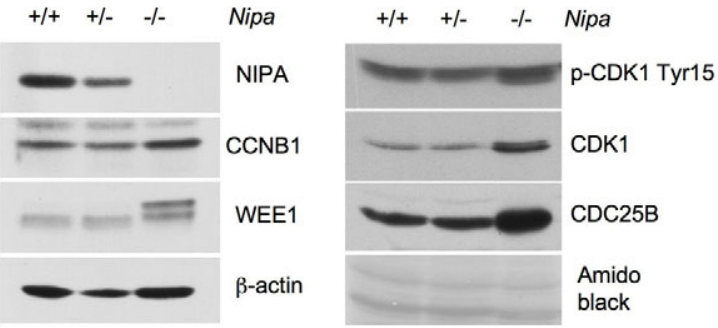

$\mathrm{F}$
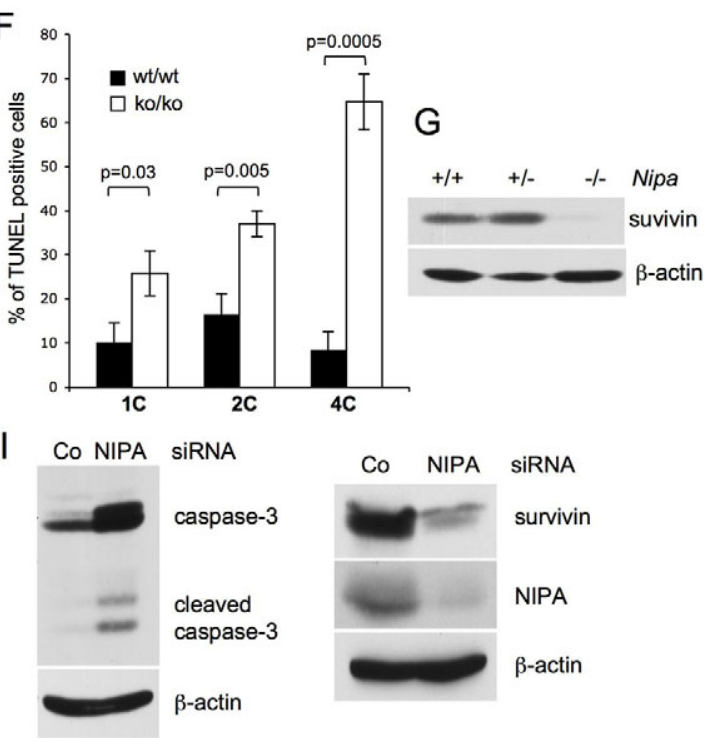

Fig. 3. NIPA deficiency leads to accumulation of meiosis I cells with subsequent apoptosis. (A) Total numbers of testicular GCs per mouse isolated from 4- to 5 month-old $\mathrm{Nipa}^{+/+}(n=8), \mathrm{Nipa}^{+/-}(n=6)$ and $\mathrm{Nipa}^{-1-}(n=8)$ mice. (B) Representative DNA-flow histograms of Pl-stained testicular GC distribution pattern. Testicular GCs were enriched at different days and stained to study the first wave of GC development. Cell populations with different DNA content are shown as haploid, diploid and tetraploid peaks. (C) Quantification of three different experiments shown in B of 2-month-old animals. (D) RT-PCR analyses of spermatogenesis-related genes. RTPCR of $\beta$-actin and Gata 1 confirmed equivalent amounts of RNA and contamination with sertoli cells, respectively. (E) Immunoblot analysis of proteins involved in $\mathrm{G}_{2} / \mathrm{M}$ transition in testicular cells lysates (40 dpp). (F) TUNEL flow cytometry analysis of GCs. Quantification of TUNELpositive spermatocytes of various DNA content (1C, 2C, 4C) (n=6). (G) Immunoblot analysis of the IAP protein survivin in $40 \mathrm{dpp}$ testis. $(\mathbf{H}, \mathbf{I})$ TUNEL $(\mathrm{H})$ and immunoblot $(\mathrm{I})$ analysis of HeLa cells transfected with control or Nipa siRNA. In $A, C, F, H$, data are mean \pm s.e.m. 
set in wild-type animals. In marked contrast, $\mathrm{Nipa}^{-/-}$mice displayed a massive reduction of cells after the meiotic divisions, resulting in a lack of haploid $1 \mathrm{C}$ cells. $\mathrm{Nipa}^{-/-}$GCs arrested in meiosis I, as demonstrated by a relative accumulation of the $4 \mathrm{C}$ population at 23 and $40 \mathrm{dpp}$. Quantification revealed more than $50 \%$ of $\mathrm{Nipa}^{-1-}$ testicular cells with 4C DNA content (Fig. 3C). In agreement with these data, RT-PCR analyses of $60 \mathrm{dpp} \mathrm{Nipa}^{-/}$ testis showed a distinct downregulation of markers for meiotic and postmeiotic cells, i.e. transition protein 1 (Tp1; Tnp1 - Mouse Genome Informatics), protamine 1 and 2 (Prm1, Prm2), and cAMP-responsive element modulator ( $\mathrm{Crem}$ ) (Fig. 3D). The expression profile of $\mathrm{Nipa}^{-/-}$testicular cells showed high amounts of mitotic/meiotic proteins such as CDK1, CDC25B, phosphorylated WEE1 and CCNB1 (Fig. 3E), which could be due either to the different composition of testicular cells in $\mathrm{Nipa}^{-/}$ testis, where relatively more mitotic spermatogonia and early meiotic spermatocytes are present compared to wild type, or to changes in protein abundance in a particular cell type.

The progressive degeneration of $\mathrm{Nipa}^{-/-}$testicular GCs prompted us to determine whether the meiotic arrest causes apoptosis. IHC analysis with activated caspase 3 antibody showed apoptosis of $\mathrm{Nipa}^{-/-}$spermatocytes starting at $10 \mathrm{dpp}$ (supplementary material Fig. S12). In agreement with this and with the histological examination, TUNEL assays of enriched GCs showed positivity in $35 \%$ of $\mathrm{Nipa}^{-/-}$cells (supplementary material Fig. S13), which was restricted to spermatocytes. In addition, combined TUNEL/DNAcontent analysis revealed that TUNEL positivity largely occurred in the $4 \mathrm{C}$ population of $\mathrm{Nipa}^{-/-}$testicular cells $(65 \%)$, whereas the $2 \mathrm{C}$ and $1 \mathrm{C}$ populations were affected to a lesser extent (Fig. 3F). Moreover, $\mathrm{Nipa}^{-/}$testicular cells displayed markedly decreased expression of survivin, an IAP-family member whose downregulation is associated with mitotic catastrophe (Castedo et al., 2004) (Fig. 3G). Thus, these results suggest that NIPA deficiency induces stage IV arrest resulting in apoptosis of the arrested spermatocytes.

In addition to our studies on the role of NIPA in somatic cells, the effects of NIPA deficiency was also analyzed in MEFs. These experiments revealed no specific cell-cycle phenotype (supplementary material Figs S14-S17). The lack of phenotype may be due to the low physiological expression of NIPA in MEFs (see Fig. 1D), suggesting that CCNB1 abundance is regulated by alternative mechanisms in MEFs. We therefore sought to investigate cells with impaired checkpoints or possibly subtle defects in their CCNB1 regulation machinery, which might be more dependent on $\mathrm{SCF}^{\mathrm{NIPA}}$ to guarantee correct cell division. To this end, we performed siRNA-mediated knockdown of NIPA in the tumor-derived HeLa cell line. This resulted in marked TUNELpositive apoptosis (Fig. 3H) associated with caspase 3 activation and survivin downregulation (Fig. 3I) similar to the results observed in $\mathrm{Nipa}^{-/-}$spermatocytes.

\section{NIPA deficiency leads to premature increase of $\mathbf{G}_{2} / \mathbf{M}$-kinase-activity}

To further investigate the role of NIPA in meiosis, we examined expression and activity of CCNB1, a previously described substrate of the $\mathrm{SCF}^{\mathrm{NIPA}}$ complex. As expected, cytoplasmic staining of CCNB1 was visible both in wild-type and heterozygous GCs (Fig. 4A). Strikingly, $\mathrm{Nipa}^{-/-}$testicular cells showed accumulation of CCNB1 in the nucleus, the subcellular compartment where the $\mathrm{SCF}^{\mathrm{NIPA}}$ complex regulates $\mathrm{CCNB} 1$ abundance (Fig. 4A). In accordance with function of NIPA as an ubiquitin-ligase of CCNB1 in murine cells, binding analyses revealed a specific interaction between the two murine proteins (Fig. 4B,C). To rule out the possibility that nuclear CCNB1 accumulation was merely a consequence of a specific cell cycle arrest in meiosis, where high CCNB1 levels are present, we analyzed CCNB1/CDK1 activity in GCs stimulated to enter $\mathrm{G}_{2} / \mathrm{M}$ in culture. To this end, we stimulated enriched GCs culture, isolated at $10 \mathrm{dpp}$ from $\mathrm{Nipa}^{+/+}$and $\mathrm{Nipa}^{-/-}$ males, with okadaic acid (OA), which has previously been shown to promote chromosome condensation and increased H1-kinase activity in mouse spermatocytes (Sette et al., 1999; Wiltshire et al., 1995), as well as in mitotic cells of the testis (Cobb et al., 1999). Stimulation of $\mathrm{Nipa}^{+/+}$cells led to an increase in H1-kinase activity after 1 hour, with a maximum (twofold) after 2.5-5 hours, in accordance with previous reports. By contrast, OA stimulation of $\mathrm{Nipa}^{-/-}$cells induced a more rapid, elevated and sustained (2.6-fold after only $30 \mathrm{~min}$ ) H1-kinase activity when compared with wildtype cells (Fig. 4D; supplementary material Fig. S18). Intriguingly, basal H1-kinase activity in $\mathrm{Nipa}^{-/-}$cells was increased. Thus, untimely nuclear CCNB1 accumulation may lead to premature $\mathrm{G}_{2} / \mathrm{M}$-kinase activity and one may speculate that this could cause meiotic arrest with subsequent apoptosis of $\mathrm{Nipa}^{-/}$GCs.

We next investigated the impact of NIPA deficiency on CCNB1 levels in somatic tissues. In particular, we focused on non-cycling tissues (liver, brain) to rule out cell cycle-dependent effects on CCNB1 abundance. These experiments revealed that deletion of NIPA leads to a significant accumulation of CCNB1 both in brain (Fig. 4E) and liver tissue (supplementary material Fig. S19) of adult $\mathrm{Nipa}^{-/-}$mice. As we did not isolate cell subpopulations of the respective tissues, we cannot exactly determine the specific cell type that contributes to the observed CCNB1 accumulation.

\section{NIPA deficiency leads to an aberrant progression of prophase-I cells}

In order to examine further the characteristics of meiotic arrest, we performed immunofluorescence analyses of chromosome spreads of $16 \mathrm{dpp}$ spermatocytes (Fig. 5A-P). During meiotic prophase, homologous chromosome pairing is stabilized by the synaptonemal complex (SC) and synapsis can be monitored by following deposition of the lateral element (anti-SYCP3, Fig. 5A) and the axial element (anti-SYCP1, Fig. 5B). At pachynema, homologous autosomes are fully synapsed along their length, which is marked by completely overlapping SYCP3 and SYCP1 staining (Fig. 5D). By contrast, late zygonema/pachynema $\mathrm{Nipa}^{-1-}$ cells showed chromosome synapsis defects (Fig. 5E-P). These were indicated by the presence of pachynema-like cells, characterized by several unsynapsed chromosomes in combination with fully synapsed bivalents (Fig. 5H,P), and by interruptions of the SYCP3/SYCP1 staining along the SC formation. In some cases, SYCP3/SYCP1 stretches were dissociated from each other (SC fragments), suggesting that chromosome fragmentation might have occurred (Fig. 5H,L, arrowheads). In other cases, stretches were close to each other (Fig. 5H,L, arrows), suggesting defects in SC deposition or localized SC disassembly (SC gaps). To quantify these observations, we counted the number of late zygonema/pachynema cells with aberrant morphology, including incomplete synapsis, SC fragments and SC gaps. As seen in Fig. 5Q, more than $60 \%$ of $\mathrm{Nipa}^{-/}$cells displayed an aberrant morphology, pointing to a severe defect in meiotic progression. Furthermore, quantification of cells with interruptions of SYCP3/SYCP1 staining at pachynema (Fig. 5R) revealed major deficits in SC appearance in $\mathrm{Nipa}^{-/-}$cells with $4.28 \pm 0.05$ interruptions/cell $(n=123)$ versus $0.76 \pm 0.45(n=123)$ in wild-type animals. 


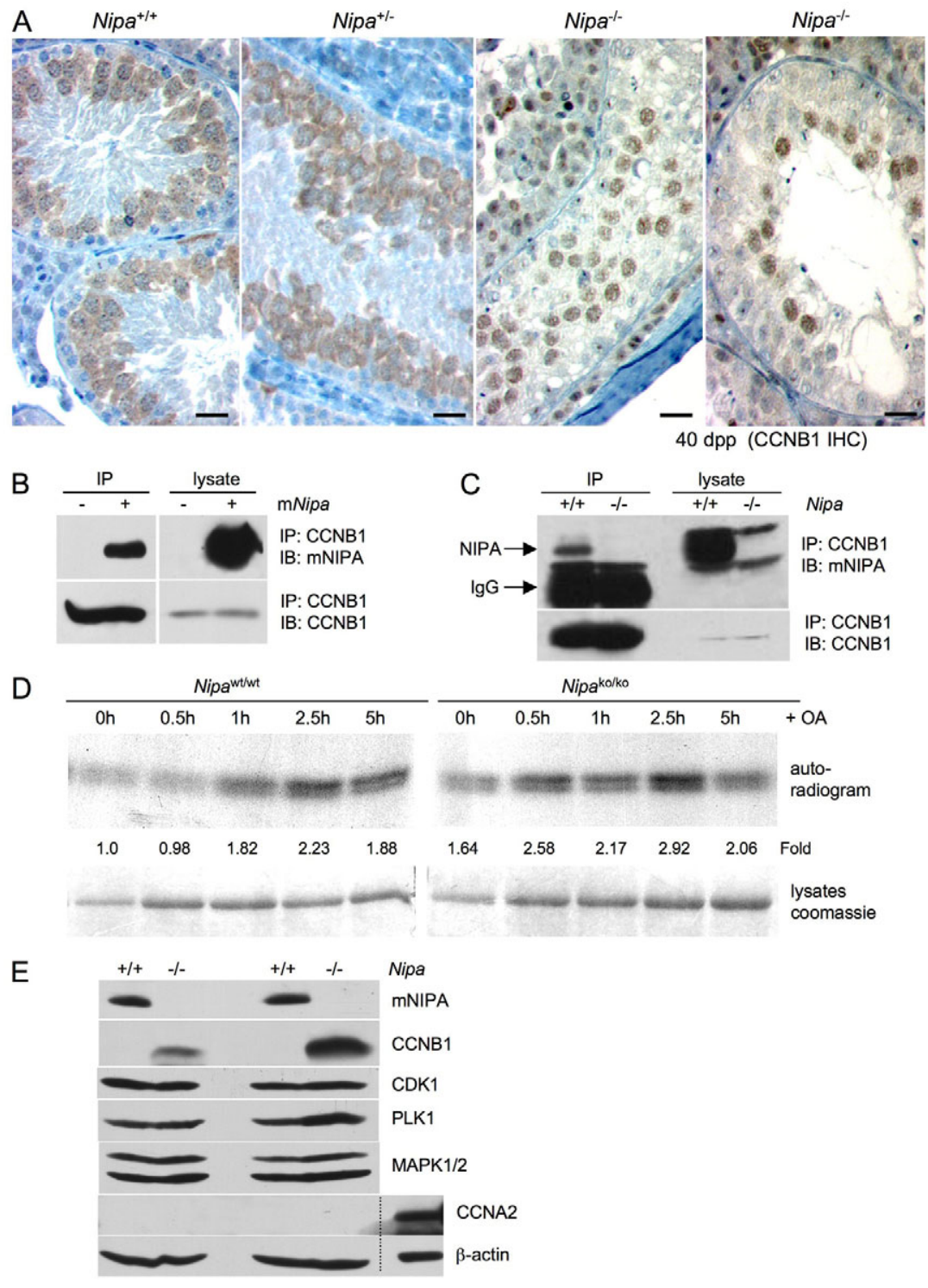

Fig. 4. NIPA deficiency leads to CCNB1 accumulation in various organs and premature $\mathbf{G}_{2} / \mathbf{M}$ kinase activity. (A) CCNB1 immunostaining of $40 \mathrm{dpp}$ testes. Control testes displayed cytoplasmic staining pattern, whereas $\mathrm{Nipa}^{-/-}$GCs showed nuclear CCNB1 accumulation. Scale bars: $25 \mu \mathrm{m}$. (B) Coimmunoprecipitation of murine NIPA (overexpressed) and CCNB1 in transiently transfected 293 cells. (C) $\mathrm{Nipa}^{+/+}$and $\mathrm{Nipa}^{-/-}$MEFs lysates were immunoprecipitated using CCNB1 antibody, then immunoblotted using NIPA or CCNB1 antibodies. (D) $\mathrm{H} 1$ kinase assay of cell extracts from $\mathrm{Nipa}^{+/+}$and $\mathrm{Nipa}^{-1-}$ mouse spermatocytes treated with $5 \mu \mathrm{M}$ OA for the indicated time. Kinase activity of the respective lysates was measured by [32P] incorporation in the autoradiogram (upper panel), quantification was calculated in relation to substrate (histone) input. Triplicate experiments were performed and additional datasets are shown in supplementary material Fig. S18. Equal lysate input was assured by protein measurement. (E) Immunoblot analysis demonstrate CCNB1 accumulation in brain extracts of $\mathrm{Nipa}^{-1-}$ mice (left panel, 6-month-old littermates; right panel, 1.5year-old littermates). Comparable CCNA, PLK1 and CDK1 protein levels eliminate cell cycle effects; $\beta$-actin confirms equal loading

\section{Synaptonemal complex structure defects in $\mathrm{Nipa}^{-/-}$ spermatocytes}

To further analyze the defect in SC formation and fragmentation, we stained chromosome spreads with SYCP3 and the telomeremarker TRF1. As seen in Fig. 6A-D, all wild-type chromosomes have two TRF1 foci at the end of each paired chromosomes, whereas $\mathrm{Nipa}^{-/-}$spermatocytes show aberrant chromosome pairing (Fig. 6E-H) with homologous chromosomes showing only one TRF1 focus (Fig. 6I), and paired homologs with two TRF1 foci but a SYCP3 interruption (Fig. 6J), which is most probably not a broken chromosome but a SYCP3 deposition defect.

To characterize SC interruptions as potential chromosome structure defects, we examined staining of STAG3, a meiosisspecific cohesin subunit that is axis associated (Fig. 6K-P). Analysis of $14 \mathrm{dpp}$ spermatocytes revealed SC gaps or fragments of the SYCP3 staining in 23\% of $\mathrm{Nipa}^{--}$chromosomes. Importantly, we found that SYCP3 staining gaps were almost always associated with gaps in the STAG3 staining (132 of 158 SYCP3 anomalies or $83 \%$ ) (Fig. 6N-P). The remaining fraction was mostly represented by SYCP3 gaps not associated with gaps in the STAG3 staining. In addition, SYCP3 fragments in 14 and 16 dpp $\mathrm{Nipa}^{-/-}$mice, which are completely separated from other chromosomes and not included in the 'gap'-class, always colocalized with STAG3, suggesting that the integrity of the chromosome axis might be compromised in $\mathrm{Nipa}^{-/-}$spermatocytes.

\section{Nipa-deficient mice display normal meiotic sex chromosome inactivation}

Sex chromosomes are transcriptionally silenced during prophase by meiotic sex chromosome inactivation (MSCI). One key event in MSCI is H2AX (H2afx - Mouse Genome Informatics) phosphorylation by ATR. Indeed, if H2AX is absent or H2AX phosphorylation $(\gamma \mathrm{H} 2 \mathrm{AX})$ does not occur properly, this results in ectopic expression of XY-linked genes with consequent elimination of spermatocytes at stage IV (Barchi et al., 2005; FernandezCapetillo et al., 2003; Ichijima et al., 2011). To examine whether the apoptotic elimination in Nipa-deficient spermatocytes is due to defects in MSCI, we analyzed $\gamma \mathrm{H} 2 \mathrm{AX}$-staining on sex chromatin. Our analysis revealed a normal pattern of $\gamma \mathrm{H} 2 \mathrm{AX}$, suggesting that MSCI occur normally (data not shown). To further challenge our interpretation, we stained chromosome spreads with an antibody that recognize RBMY, a Y-linked gene. The analysis revealed no 


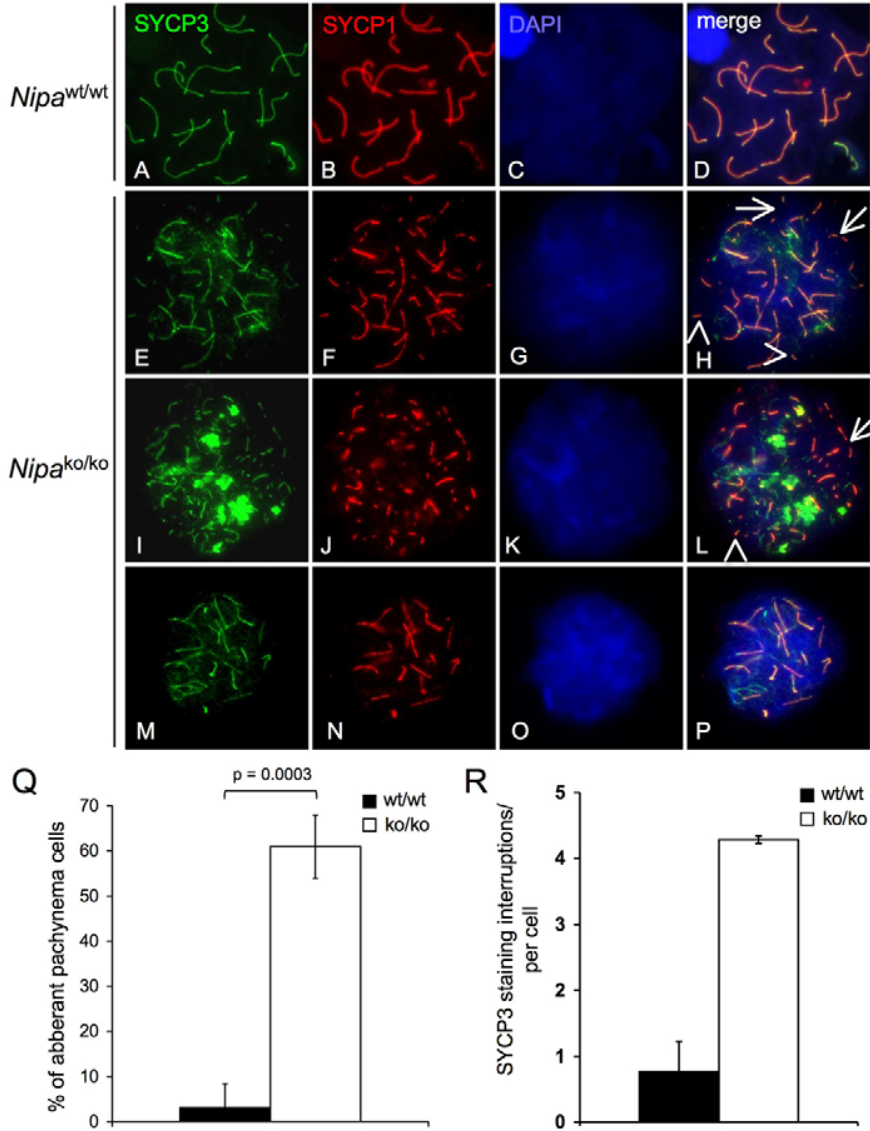

Fig. 5. NIPA deficiency leads to an aberrant progression of prophase I cells. (A-P) Wild-type (A-D) and $\mathrm{Nipa}^{-1-}$ (E-P) chromosome spreads were immunostained with antibodies recognizing SYCP3 and SYCP1. Nipa ${ }^{-1-}$ late zygonema/pachynema cells show many abnormalities of SC assembly, including apparent SYCP3 polycomplexes and low colocalization of SYCP1/3 staining Interruptions of SYCP3/SYCP1 staining with dispersed short fragments (arrowheads in $\mathrm{H}, \mathrm{L}$ ) and conjuncted short fragments (arrows in $\mathrm{H}, \mathrm{L}$ ) can be seen. (Q) Quantification of pachynema cells shows $60.9 \%$ of $\mathrm{Nipa}^{-1-}$ spermatocytes with aberrant morphology compared with 3.06\% of control cells. (R) Quantification of SYCP3/1 staining interruptions. Data are mean \pm s.e.m.

differences in pachytene $\mathrm{Nipa}^{-/-}$and $\mathrm{Nipa}^{+/+}$spermatocytes (Fig. 6Q-S), whereas $H 2 a f x^{-/}$pachynema spermatocytes were RBMY positive (Fernandez-Capetillo et al., 2003) and indicate that NIPA is dispensable for correct MSCI.

\section{Nipa-deficient mice display a delay in the repair of double strand breaks}

The disappearance of double-stranded break (DSB) markers from meiotic chromatin is coincident with synapsis (Mahadevaiah et al., 2001), so the synapsis defect in $\mathrm{Nipa}^{-/-}$mice led us to test whether these cells are defective in the repair of dsDNA breaks. DSB repair can be followed indirectly by staining chromosomes for $\gamma \mathrm{H} 2 \mathrm{AX}$ (Mahadevaiah et al., 2001), and for strand-exchange proteins RAD51 and DMC1, which form cytological complexes at sites of ongoing recombination (Moens et al., 1997; Plug et al., 1996). During zygonema, the number of RAD51/DMC1 foci peaks and $\gamma \mathrm{H} 2 \mathrm{AX}$ progressively disappears where synapsis has occurred. In early pachynema, most of these early DSB markers have disappeared from autosomes and only few of RAD51/DMC1 foci remain on the unsynapsed regions (Fig. 7A-C) along with the DSBindependent $\gamma \mathrm{H} 2 \mathrm{AX}$ in the sex body. In our analysis (Fig. 7J), 16 dpp pachytene-like $\mathrm{Nipa}^{-/-}$spermatocytes displayed appreciably more DMC1 foci with $93.56 \pm 9.2$ foci versus $50 \pm 4.41$ foci in wildtype early pachynema cells, where essentially all DMC1 foci disappeared in late pachynema. The increase in number of DMC1 foci might be due to a delay in DSB repair or the consequence of the arrest of Nipa-deficient spermatocytes. To distinguish between these two possibilities, we analyzed an earlier time point during the first wave of spermatogenesis (14 dpp) and compared the number of $\mathrm{Nipa}^{-/-} \mathrm{DMC1}$ foci at pachynema with that of early-pachynema (H1t-negative) wild-type cells. The analysis revealed an even more pronounced increase in DMC1 foci number in $\mathrm{Nipa}^{-/-} 14 \mathrm{dpp}$ (121.55 foci/cell) mice (Fig. 7C,F,J), where early pachynema cells first appear, indicating a delay in the repair of DSB. In adult $\mathrm{Nipa}^{-1-}$ mice, some mid-pachynema H1t-positive cells were present. Importantly, these cells show normal levels of DMC1 foci (Fig. 7G-I), so it is most likely that these cells escape the arrest and - as cause or consequence - successfully repair their DSBs.

Moreover, we asked whether the SC fragmentation and possible chromosome axis defects colocalize with sites of unrepaired DNA DSBs. Intriguingly, many SYCP3 abnormalities (interruptions or gaps) were associated with cytological markers for DSB repair. DMC1 foci were found at one or both ends of the SYCP3 staining interruption at an average of 2.06 interruptions per cell or $47.7 \%(n=105)$ of the interruptions were associated with DMC1 (Fig. 7K) in $\mathrm{Nipa}^{-/-}$animals, whereas wild-type mice show an average of 0.16 interruptions with DMC1 colocalization ( $n=105)$ (Fig. 7L).

To summarize, wild-type pachynema spermatocytes are fully synapsed and SC interruptions occur only occasionally and are not related to DMC1 labeling. By contrast, $\mathrm{Nipa}^{-/-}$animals show a significantly higher rate of SC interruptions and nearly $50 \%$ of the SYCP3 abnormalities are associated with DMC1, suggesting a possible mechanistic link between chromosome axis defects and the ongoing process of DNA repair.

\section{DISCUSSION}

Although previous studies investigated the consequences of constitutively active SCF ${ }^{\mathrm{NIPA}}$ (Bassermann et al., 2005b), we here studied the effect of NIPA deficiency in vivo and found that ablation of NIPA has profound consequences for the meiotic cell division.

\section{Nipa deficiency leads to accumulation of CCNB1 in vivo}

$\mathrm{Nipa}^{-/-}$GCs showed high levels of CCNB1 in the nucleus, the subcellular compartment where $\mathrm{SCF}^{\mathrm{NIPA}}$ regulates $\mathrm{CCNB} 1$ abundance (Bassermann et al., 2007; Bassermann et al., 2005b; von Klitzing et al., 2011). Other non-cycling tissues such as brain and liver showed high levels of CCNB1, consistent with the previous described function of the $\mathrm{SCF}^{\mathrm{NIPA}}$ complex. However, we found $\mathrm{Nipa}^{-/-}$mice to be viable even though smaller and MEFs displayed no clear cell cycle phenotype. It has previously been shown that NIPA acts as a safeguard mechanism in CCNB1 regulation, preventing untimely nuclear CCNB1 accumulation (Bassermann et al., 2005b). Primary cells, which have appropriate CCNB1 regulation independent of $\mathrm{SCF}^{\mathrm{NIPA}}$, appear to be able to compensate for the loss of NIPA. Conversely, cells with impaired checkpoints or subtle defects in their CCNB1 regulation machinery might be more dependent on $\mathrm{SCF}^{\mathrm{NIPA}}$ to guarantee correct cell 

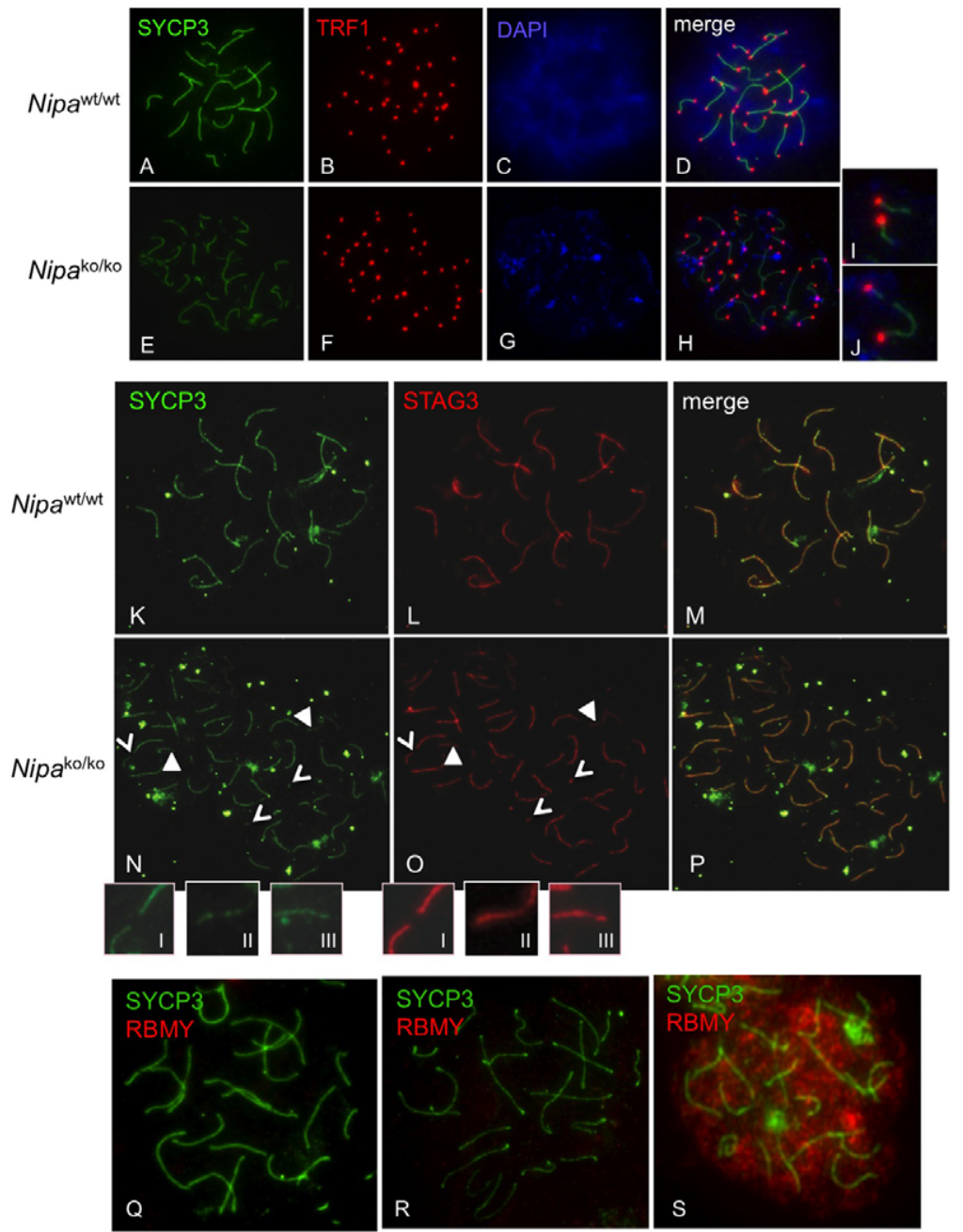

Nipa ${ }^{\text {wtwt }}$

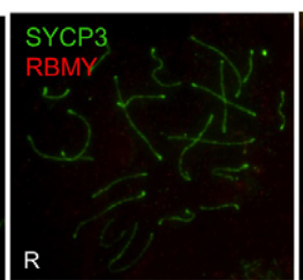

Nipako/ko

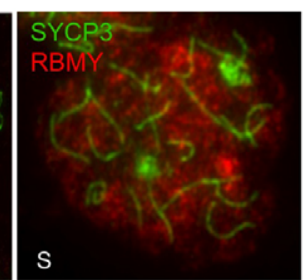

$H 2 a f x^{k o / k o}$
Fig. 6. $\mathrm{Nipa}^{-1-}$ mice display synaptonemal complex structure defects without abnormalities in $\mathrm{MSCl}$. (A-J) Nipa ${ }^{+/+}$(A-D) and $\mathrm{Nipa}^{-/-}$(E-J) chromosome spreads stained with SYCP3 and TRF1. Nipa ${ }^{-1-}$ spermatocytes showed aberrant homologs displaying one TRF1 focus (I) or paired homologs with two TRF1 foci but abnormal SYCP3 interruption (J). (K-P) Chromosome spreads from $14 \mathrm{dpp}$ $\mathrm{Nipa}^{+/+}(\mathrm{K}-\mathrm{M})$ and $\mathrm{Nipa}^{-/-}$(N-P) were immunostained with SYCP3 and STAG3 antibodies. Arrowheads ( $\mathrm{N}, \mathrm{O}$, insets I) indicate gaps in SYCP3 staining, which colocalize with gaps in STAG3 staining. Open arrowheads $(\mathrm{N}, \mathrm{O})$ indicate short fragments of SYCP3/STAG3 staining. Insets II,III $(\mathrm{N}, \mathrm{O})$ are regions where we observed a gap in the SYCP3 staining in the absence of a detectable STAG3 staining defect or, conversely, regions with thinning of STAG3 staining in the absence of a visible SYCP3 deposition defect. $(\mathbf{Q}, \mathbf{R})$ Staining with the Y-linked gene RBMY revealed normal inactivation of $\mathrm{Nipa}^{-/-}$and $\mathrm{Nipa}^{+/+}$pachytene spermatocytes. (S) H2afx knockout spreads served as a positive control and showed strong RBMY expression. division. This notion is supported by our experiments in the tumor cell line HeLa, where we show that NIPA knockdown leads to premature mitotic entry and subsequent apoptosis.

Another explanation for the lack of a clear cell cycle phenotype in MEFs can be the relatively low expression of NIPA in MEFs. Interestingly, NIPA is highly expressed in early pachytene spermatocytes and expression data demonstrate that CCNB1 levels are also highest in pachytene spermatocytes (Chapman and Wolgemuth, 1994). Any failure in the CCNB1 regulatory machinery may therefore have substantial consequences at this stage of differentiation and cannot be compensated for by other CCNB1 regulation factors. The reduction of body weight in Nipadeficient animals could either be connected to cell cycle defects or is more likely to be the result of hormone deprivation resulting from testis and ovarial atrophy. Taken together, the NIPA knockout mouse substantiates previously published studies (Bassermann et al., 2007; Bassermann et al., 2005b; von Klitzing et al., 2011) and shows the primary physiological function of NIPA as an important ubiquitylation factor of CCNB1 in vivo.

\section{NIPA is required for proper meiosis in male and female mice}

The primary finding of this study is the phenotype of male infertility and female subfertility with arrest of the meiotic prophase. Virtually no spermatocytes progress beyond a late zygotene to early pachytene stage and reach an aberrant pachynema stage, where the SC is not assembled properly with incomplete synapsis and SYCP3 polycomplexes. Meiotic asynapsis (as well as unrepaired damage, see below) is not tolerated in mammalian spermatogenesis and all meiotic 'asynaptic' mutants that have been examined so far arrest in an epithelial stage IV checkpoint (Barchi et al., 2005; de Rooij and de Boer, 2003). In accordance with this, $\mathrm{Nipa}^{-/-}$spermatocytes become apoptotic in epithelial stage IV, although some rare knockout spermatocytes get past the arrest. Epithelial stage IV apoptosis is also triggered by a failure in MSCI (Royo et al., 2010). However, MSCI seems to occur normally in absence of NIPA, pointing to chromosome synapses defects as one primary cause of spermatocyte elimination. Another important finding in $\mathrm{Nipa}^{-/-}$testis is the empty appearance of the seminiferous tubules in older mice, demonstrating a progressive testicular atrophy with fibrosis and a Sertoli-only syndrome-like appearance. This may argue for an additional mitotic failure of $\mathrm{Nipa}^{-/-}$spermatogonia beyond the role of the protein in meiosis. However, as our knockout strategy does not differentiate between ubiquitously expressed NIPA having a functional role in GCs or in other cell types that regulate gametogenesis (e.g. sertoli cells, leydig cells, granulosa cells), indirect effects of the GCsurrounding compartment cannot be excluded.

Previous reports on the inactivation of other important mitotic cell cycle regulators (FBPs, CDKs, cyclins and CDK inhibitors) (Cardozo and Pagano, 2004) showed additional spermatogenesis 

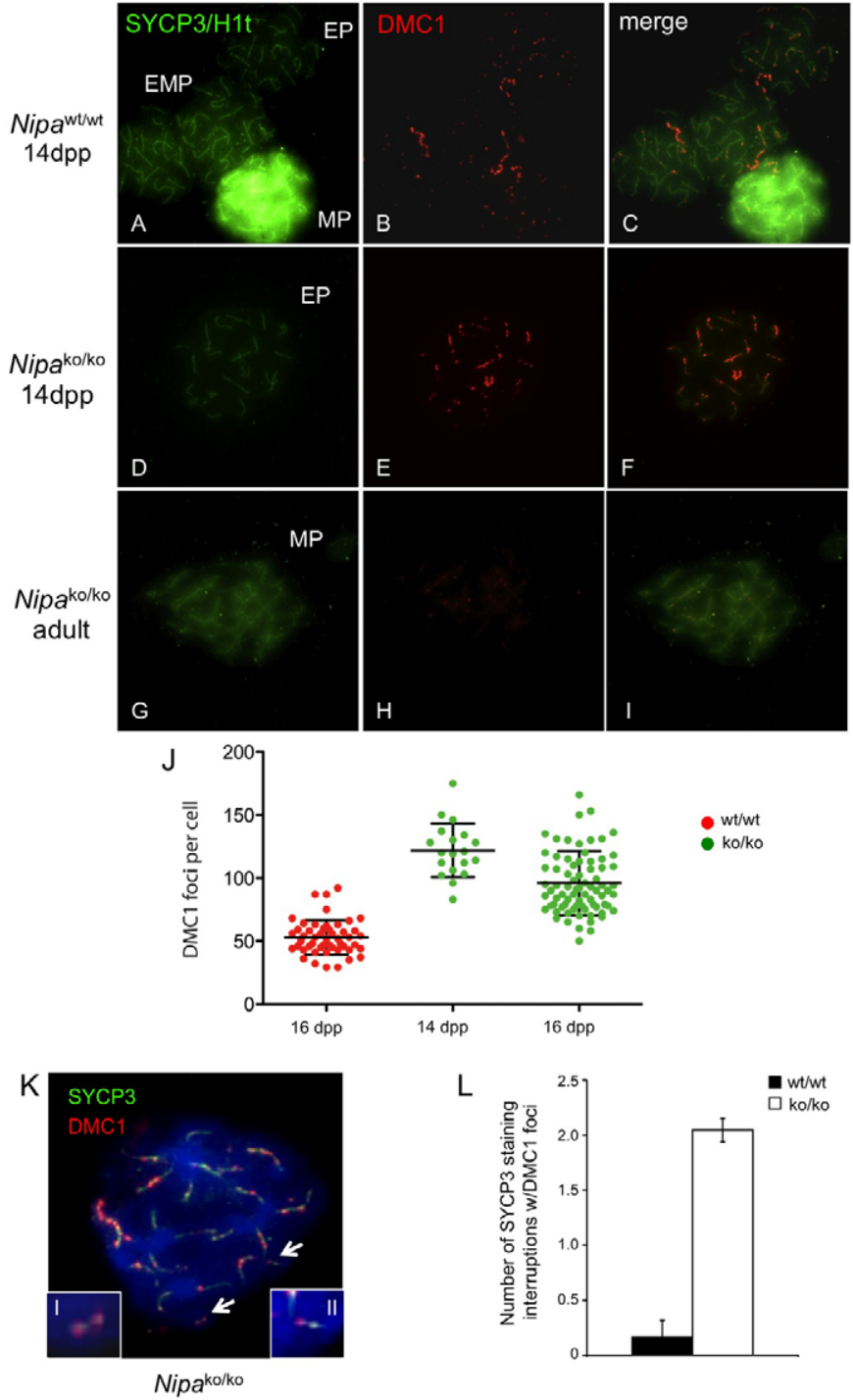

Fig. 7. $\mathrm{Nipa}^{-/-}$mice display a defect/delay in the repair of DNA DSBs. (A-I) Chromosomal spreads of $14 \mathrm{dpp}(\mathrm{A}-\mathrm{F})$ and adult (G-I) mice were stained with SYCP3 and DMC1 (EMP, early mid-pachynema; EP, early pachynema; MP, mid pachynema). (J) Number of DMC 1 foci in EP cells of $\mathrm{Nipa}^{+/+}$and $\mathrm{Nipa}^{-/-}$mice were counted to look for a general defect/delay in DSB repair. Quantification of three independent mice per genotype and age. (K) Colocalization of chromosome axis defects (SYCP3 interruptions) with marker of DSB repair (DMC1 foci) in Nipa ${ }^{-/}$ spermatocytes isolated at $16 \mathrm{dpp}$. Arrows and magnifications (insets) indicate SYCP3 fragments colocalizing with two (I) or one (II) DMC1 foci. (L) Quantification revealed that 2.06 SCYP3 interruptions/cell $(n=105)$ are associated with DMC 1 foci, versus $0.16(n=105)$ in wild type. Data are mean \pm s.e.m.

defects, reflecting similar mechanisms in mitotic and meiotic regulation. Accordingly, Btrc-deficient mice displayed defective spermatogenesis with accumulation of metaphase I spermatocytes (Guardavaccaro et al., 2003), Cdk2 (cyclindependent kinase 2)-deficient spermatocytes proceed to the end of prophase I of the meiotic division (Ortega et al., 2003) and cyclin E2-deficient animals have also extensive apoptosis of spermatocytes, taking place especially in the meiotic divisions (Geng et al., 2003).

\section{NIPA deficiency leads to aberrant SC assembly}

Successful completion of meiosis in mice depends on the assembly of the SC (Jessberger, 2002). Importantly, there is evidence that CCNB1/CDK1 kinase activity is needed for correct SC disassembly (Dix et al., 1997). Premature MPF activity could lead to precocious SC disintegration, followed by an arrest of spermatocytes due to checkpoint activation, and to apoptotic elimination at stage IV. Intriguingly, besides nuclear CCNB1 accumulation, we found evidence of increased basal level of H1kinase activity in $\mathrm{Nipa}^{-/-}$testicular cells. One may speculate that untimely activation of CCNB1/CDK1 have led to premature onset of meiotic cell division. Consequently, $\mathrm{Nipa}^{-/-}$zygotene and early pachytene spermatocytes fail to complete meiotic prophase by aberrant SC formation and asynapsis, thereafter arrest at the epithelial stage IV checkpoint and undergo apoptosis. Leptonema/zygonema cells are not competent to respond to OA with increase in H1-kinase activity (Cobb et al., 1999). Therefore, increased $\mathrm{H} 1$ activity after OA treatment in $\mathrm{Nipa}^{-/-}$testicular cell suspension is most likely to be due to mitotic dividing spermatogonia, which could be an explanation for the loss of spermatogonia in older Nipa-deficient animals.

\section{Role of NIPA in DNA repair, SC-fragmentation and chromosome axis defects}

Here, we report that $\mathrm{Nipa}^{-/}$meiocytes exhibit persistent cytological markers for DSB repair proteins in meiotic prophase with more than twice as many DMC1 foci as control animals. This could be either a consequence of stage IV arrest, where $\mathrm{Nipa}^{-/-}$ spermatocytes do not progress to the point where DSBs are removed from paired chromosomes, or due to delayed repair of DNA DSBs. Kinetic analysis of the first wave of spermatogenesis showed increased DMC1 foci in $\mathrm{Nipa}^{-/-}$cells as soon as early pachynema cells appear (13-14 dpp), thus arguing for an involvement of NIPA in the repair of DSBs. Moreover, we show a subpopulation of rare $\mathrm{Nipa}^{-/-}$spermatocytes that passes early pachynema and get to mid-pachynema without any aberrant increase in DMC1/RAD51 foci, implying that some of the knockout spermatocytes can fully repair their DSBs and DMC1 foci persist only in the sex chromosomes. These cells are most likely to be the ones that pass the stage IV arrest and eventually become round spermatids.

Nipa-deficient spermatocytes exhibit numerous abnormalities in SYCP3 and STAG3 staining, indicating that possible chromosome axis defects (discontinuities in SYCP3 staining) were often associated with compromised chromosome axis integrity (discontinuities in STAG staining), leading to overt chromosome fragmentation. One possible explanation for these observations could be that 'weak spots' on axes are susceptible to disruptive forces from chromosome spreading procedures, resulting in extreme stretching or even complete severing of the DNA from all four chromatids. Alternatively, stretching and/or chromatid severing occur in vivo, perhaps as a consequence of large-scale chromosome movements that have been documented during meiotic prophase in some organisms (Scherthan et al., 2007).

The frequent association of abnormalities in SYCP3 staining and DSB markers (DMC1 foci) suggests a possible mechanistic link between inappropriate $\mathrm{SC}$ fragmentation and the ongoing process of DSB repair. This phenotype shares similarities with the $\mathrm{Atm}^{-1-} \mathrm{Spo}^{+1^{+-}}$mice (Barchi et al., 2008) in many aspects, where chromosome fragmentation is coincident with defects in DSB repair. Moreover, we show that Nipa deficiency does not lead to a 
defect in MSCI, despite epithelial stage IV apoptosis. To our knowledge (besides Trip13 mutant) $\mathrm{Nipa}^{-/}$knockout mice represent one of the few male mutants in which a defect in MSCI is not involved in the activation of the checkpoint response that leads to stage IV apoptosis. This observation indirectly supports our model, in which elimination of $\mathrm{Nipa}^{-/-}$spermatocytes is due to activation of a checkpoint monitoring synapsis and proper DNAdamage repair.

$\mathrm{Nipa}^{-/-}$females are subfertile with early and severe meiotic defect during embryogenesis. It has been shown that elimination of oocytes during embryogenesis can be due to DNA damageindependent (synapsis defects in Spo11 $1^{-/-}$mice) and -dependent checkpoints (Dmcl-, Msh5-knockout mice) (Di Giacomo et al., 2005). As we did not look at SC assembly or DSB repair in mutant females, one can only speculate that elimination of Nipa-deficient oocytes is triggered by one of these two checkpoints or the combination of both.

Taken together, the phenotype of Nipa-knockout mice is a definitive proof of the meiotic significance of NIPA. Arrest and apoptosis from Nipa-deficient spermatocytes is most probably the result of two different - or combined - mechanisms: one reason of meiotic failure in $\mathrm{Nipa}^{-/-}$spermatocytes is the upregulation of CCNB1, which leads to SC disassembly, premature CCNB1/CDK1 kinase activity and activation of a checkpoint, which is triggered by defects in homologues chromosome synapsis (Baudat et al., 2000; Odorisio et al., 1998). The other reason could be defective chromosome axis stability of Nipa-mutant spermatocytes, leading to a defect/delay in DSB repair and inappropriate SC fragmentation, thereby activating the DNA damage-dependent checkpoint with subsequent apoptosis. The latter might be a CCNB1 independent effect and one may speculate the involvement of a new, still unknown, substrate of the $\mathrm{SCF}^{\mathrm{NIPA}}$ complex or alternatively a direct function of NIPA as a factor for chromosome stability.

\section{Acknowledgements}

We thank Dr Xiaoli Cui and Petra Schenk for excellent technical assistance.

\section{Funding}

These studies were supported by a grant from the Deutsche Forschungsgemeinschaft (DFG) and the Wilhelm Sander Stiftung to J.D. [2007.043.1]. A.L.I. was supported by a research grant from the Technical University of Munich [KKF-B07-08]. J.D. and A.L.I. were supported by DFG [DU227/3-1]. M.B. was supported by a grant from Associazione Italiana per la Ricerca sul Cancro (AIRC) [MFAG n. 4765]. S.W.M. was supported by grants from the National cancer Institute (NCI) [CA69129, CA21765] and by American Lebanese Syrian Associated Charities (ALSAC, St Jude Children's Research Hospital). F.B. was supported by grants from the German Research Foundation [Emmy Noether Programme, BA 2851/3-1] and German Cancer Aid [109543]. Deposited in PMC for release after 12 months.

\section{Competing interests statement}

The authors declare no competing financial interests.

\section{Supplementary material}

Supplementary material available online at

http://dev.biologists.org/lookup/suppl/doi:10.1242/dev.073072/-/DC1

\section{References}

Barchi, M., Mahadevaiah, S., Di Giacomo, M., Baudat, F., de Rooij, D. G., Burgoyne, P. S., Jasin, M. and Keeney, S. (2005). Surveillance of different recombination defects in mouse spermatocytes yields distinct responses despite elimination at an identical developmental stage. Mol. Cell. Biol. 25, 7203-7215.

Barchi, M., Roig, I., Di Giacomo, M., de Rooij, D. G., Keeney, S. and Jasin, M. (2008). ATM promotes the obligate XY crossover and both crossover control and chromosome axis integrity on autosomes. PLoS Genet. 4, e1000076.

Barchi, M., Geremia, R., Magliozzi, R. and Bianchi, E. (2009). Isolation and analyses of enriched populations of male mouse germ cells by sedimentation velocity: the centrifugal elutriation. Methods Mol. Biol. 558, 299-321.
Bassermann, F., Peschel, C. and Duyster, J. (2005a). Mitotic entry: a matter of oscillating destruction. Cell Cycle 4, 1515-1517.

Bassermann, F., von Klitzing, C., Munch, S., Bai, R. Y., Kawaguchi, H., Morris, S. W., Peschel, C. and Duyster, J. (2005b). NIPA defines an SCF-type mammalian E3 ligase that regulates mitotic entry. Cell 122, 45-57.

Bassermann, F., von Klitzing, C., Illert, A. L., Munch, S., Morris, S. W., Pagano, M., Peschel, C. and Duyster, J. (2007). Multisite phosphorylation of nuclear interaction partner of ALK (NIPA) at G2/M involves cyclin B1/Cdk1. J. Biol. Chem. 282, 15965-15972.

Baudat, F., Manova, K., Yuen, J. P., Jasin, M. and Keeney, S. (2000). Chromosome synapsis defects and sexually dimorphic meiotic progression in mice lacking Spo11. Mol. Cell 6, 989-998.

Berthet, C., Aleem, E., Coppola, V., Tessarollo, L. and Kaldis, P. (2003). Cdk2 knockout mice are viable. Curr. Biol. 13, 1775-1785.

Cardozo, T. and Pagano, M. (2004). The SCF ubiquitin ligase: insights into a molecular machine. Nat. Rev. Mol. Cell Biol. 5, 739-751.

Castedo, M., Perfettini, J. L., Roumier, T., Andreau, K., Medema, R. and Kroemer, G. (2004). Cell death by mitotic catastrophe: a molecular definition. Oncogene 23, 2825-2837.

Chapman, D. L. and Wolgemuth, D. J. (1994). Regulation of M-phase promoting factor activity during development of mouse male germ cells. Dev. Biol. 165, 500-506.

Chen, M. S., Hurov, J., White, L. S., Woodford-Thomas, T. and PiwnicaWorms, H. (2001). Absence of apparent phenotype in mice lacking Cdc25C protein phosphatase. Mol. Cell. Biol. 21, 3853-3861.

Cobb, J., Cargile, B. and Handel, M. A. (1999). Acquisition of competence to condense metaphase I chromosomes during spermatogenesis. Dev. Biol. 205 49-64.

de Rooij, D. G. and de Boer, P. (2003). Specific arrests of spermatogenesis in genetically modified and mutant mice. Cytogenet. Genome Res. 103, 267-276.

Di Giacomo, M., Barchi, M., Baudat, F., Edelmann, W., Keeney, S. and Jasin M. (2005). Distinct DNA-damage-dependent and -independent responses drive the loss of oocytes in recombination-defective mouse mutants. Proc. Natl. Acad. SCi. USA 102, 737-742.

Dix, D. J., Allen, J. W., Collins, B. W., Poorman-Allen, P., Mori, C., Blizard, D. R., Brown, P. R., Goulding, E. H., Strong, B. D. and Eddy, E. M. (1997) HSP70-2 is required for desynapsis of synaptonemal complexes during meiotic prophase in juvenile and adult mouse spermatocytes. Development 124, 45954603.

Fernandez-Capetillo, O., Mahadevaiah, S. K., Celeste, A., Romanienko, P. J., Camerini-Otero, R. D., Bonner, W. M., Manova, K., Burgoyne, P. and Nussenzweig, A. (2003). H2AX is required for chromatin remodeling and inactivation of sex chromosomes in male mouse meiosis. Dev. Cell 4, 497-508.

Geng, Y., Yu, Q., Sicinska, E., Das, M., Schneider, J. E., Bhattacharya, S., Rideout, W. M., Bronson, R. T., Gardner, H. and Sicinski, P. (2003). Cyclin E ablation in the mouse. Cell 114, 431-443.

Guardavaccaro, D., Kudo, Y., Boulaire, J., Barchi, M., Busino, L., Donzelli, M. Margottin-Goguet, F., Jackson, P. K., Yamasaki, L. and Pagano, M. (2003). Control of meiotic and mitotic progression by the $\mathrm{F}$ box protein beta-Trcp1 in vivo. Dev. Cell 4, 799-812.

Hartmann, D., de Strooper, B., Serneels, L., Craessaerts, K., Herreman, A., Annaert, W., Umans, L., Lubke, T., Lena Illert, A., von Figura, K. et al. (2002). The disintegrin/metalloprotease ADAM 10 is essential for Notch signalling but not for alpha-secretase activity in fibroblasts. Hum. Mol. Genet. $11,2615-2624$.

Hochstrasser, M. (1996). Ubiquitin-dependent protein degradation. Annu. Rev. Genet. 30, 405-439.

Ichijima, Y., Ichijima, M., Lou, Z., Nussenzweig, A., Camerini-Otero, R. D., Chen, J., Andreassen, P. R. and Namekawa, S. H. (2011). MDC1 directs chromosome-wide silencing of the sex chromosomes in male germ cells. Genes Dev. 25, 959-971

Jessberger, R. (2002). The many functions of SMC proteins in chromosome dynamics. Nat. Rev. Mol. Cell Biol. 3, 767-778.

Jeyaraj, D. A., Grossman, G., Weaver, C. and Petrusz, P. (2002). Dynamics of testicular germ cell proliferation in normal mice and transgenic mice overexpressing rat androgen-binding protein: a flow cytometric evaluation. Biol. Reprod. 66, 877-885.

Li, R. and Morris, S. W. (2008). Development of anaplastic lymphoma kinase (ALK) small-molecule inhibitors for cancer therapy. Med. Res. Rev. 3, 372-412.

Liu, P., Jenkins, N. A. and Copeland, N. G. (2003). A highly efficient recombineering-based method for generating conditional knockout mutations Genome Res. 13, 476-484

Lowry, O. H., Rosebrough, N. J., Farr, A. L. and Randall, R. J. (1951). Protein measurement with the Folin phenol reagent. J. Biol. Chem. 193, 265-275.

Mahadevaiah, S. K., Turner, J. M., Baudat, F., Rogakou, E. P., de Boer, P., Blanco-Rodriguez, J., Jasin, M., Keeney, S., Bonner, W. M. and Burgoyne, P. S. (2001). Recombinational DNA double-strand breaks in mice precede synapsis. Nat. Genet. 27, 271-276. 
Moens, P. B., Chen, D. J., Shen, Z., Kolas, N., Tarsounas, M., Heng, H. H. and Spyropoulos, B. (1997). Rad51 immunocytology in rat and mouse spermatocytes and oocytes. Chromosoma 106, 207-215.

Morris, S. W., Kirstein, M. N., Valentine, M. B., Dittmer, K. G., Shapiro, D. N., Saltman, D. L. and Look, A. T. (1994). Fusion of a kinase gene, ALK, to a nucleolar protein gene, NPM, in non-Hodgkin's lymphoma. Science 263, 1281 1284

Nakayama, K., Nagahama, H., Minamishima, Y. A., Matsumoto, M., Nakamichi, I., Kitagawa, K., Shirane, M., Tsunematsu, R., Tsukiyama, T. Ishida, N. et al. (2000). Targeted disruption of Skp2 results in accumulation of cyclin E and p27(Kip1), polyploidy and centrosome overduplication. EMBO J. 19 2069-2081.

Odorisio, T., Rodriguez, T. A., Evans, E. P., Clarke, A. R. and Burgoyne, P. S. (1998). The meiotic checkpoint monitoring synapsis eliminates spermatocytes via p53-independent apoptosis. Nat. Genet. 18, 257-261.

Ortega, S., Prieto, I., Odajima, J., Martin, A., Dubus, P., Sotillo, R., Barbero, J. L., Malumbres, M. and Barbacid, M. (2003). Cyclin-dependent kinase 2 is essential for meiosis but not for mitotic cell division in mice. Nat. Genet. 35, 2531.

Ouyang, T., Bai, R. Y., Bassermann, F., von Klitzing, C., Klumpen, S., Miething, C., Morris, S. W., Peschel, C. and Duyster, J. (2003). Identification and characterization of a nuclear interacting partner of anaplastic lymphoma kinase (NIPA). J. Biol. Chem. 278, 30028-30036.

Pines, J. and Hunter, T. (1991). Human cyclins A and B1 are differentially located in the cell and undergo cell cycle-dependent nuclear transport. J. Cell Biol. 115, $1-17$.

Plug, A. W., Xu, J., Reddy, G., Golub, E. I. and Ashley, T. (1996). Presynaptic association of Rad51 protein with selected sites in meiotic chromatin. Proc. Natl. Acad. Sci. USA 93, 5920-5924.

Rajewsky, K., Gu, H., Kuhn, R., Betz, U. A., Muller, W., Roes, J. and Schwenk, F. (1996). Conditional gene targeting. J. Clin. Invest. 98, 600-603.

Royo, H., Polikiewicz, G., Mahadevaiah, S. K., Prosser, H., Mitchell, M., Bradley, A., de Rooij, D. G., Burgoyne, P. S. and Turner, J. M. (2010) Evidence that meiotic sex chromosome inactivation is essential for male fertility. Curr. Biol. 20, 2117-2123.

Santra, M. K., Wajapeyee, N. and Green, M. R. (2009). F-box protein FBXO31 mediates cyclin D1 degradation to induce G1 arrest after DNA damage. Nature
459, 722-725

Scherthan, H., Wang, H., Adelfalk, C., White, E. J., Cowan, C., Cande, W. Z. and Kaback, D. B. (2007). Chromosome mobility during meiotic prophase in Saccharomyces cerevisiae. Proc. Natl. Acad. Sci. USA 104, 16934-16939.

Schwenk, F., Baron, U. and Rajewsky, K. (1995). A cre-transgenic mouse strain for the ubiquitous deletion of loxP-flanked gene segments including deletion in germ cells. Nucleic Acids Res. 23, 5080-5081

Sette, C., Barchi, M., Bianchini, A., Conti, M., Rossi, P. and Geremia, R. (1999). Activation of the mitogen-activated protein kinase ERK1 during meiotic progression of mouse pachytene spermatocytes. J. Biol. Chem. 274, 3357133579.

Skaar, J. R., D'Angiolella, V., Pagan, J. K. and Pagano, M. (2009a). SnapShot: F box proteins II. Cell 137, 1358.

Skaar, J. R., Pagan, J. K. and Pagano, M. (2009b). SnapShot: F box proteins I. Cell 137, 1160

Soda, M., Choi, Y. L., Enomoto, M., Takada, S., Yamashita, Y., Ishikawa, S., Fujiwara, S., Watanabe, H., Kurashina, K., Hatanaka, H. et al. (2007). Identification of the transforming EML4-ALK fusion gene in non-small-cell lung cancer. Nature 448, 561-566.

Tetzlaff, M. T., Yu, W., Li, M., Zhang, P., Finegold, M., Mahon, K., Harper, J. W., Schwartz, R. J. and Elledge, S. J. (2004). Defective cardiovascular development and elevated cyclin $\mathrm{E}$ and Notch proteins in mice lacking the Fbw7 F-box protein. Proc. Natl. Acad. Sci. USA 101, 3338-3345.

van den Hurk, R. and Zhao, J. (2005). Formation of mammalian oocytes and their growth, differentiation and maturation within ovarian follicles. Theriogenology 63, 1717-1751.

von Klitzing, C., Huss, R., Illert, A. L., Froschl, A., Wotzel, S., Peschel, C., Bassermann, F. and Duyster, J. (2011). APC/C-mediated degradation of the Fbox protein NIPA is regulated by its association with Skp1. PLOS ONE 6, e28998.

Wiltshire, T., Park, C., Caldwell, K. A. and Handel, M. A. (1995). Induced premature $\mathrm{G} 2 / \mathrm{M}$-phase transition in pachytene spermatocytes includes events unique to meiosis. Dev. Biol. 169, 557-567.

Yang, J., Bardes, E. S., Moore, J. D., Brennan, J., Powers, M. A. and Kornbluth, S. (1998). Control of cyclin B1 localization through regulated binding of the nuclear export factor CRM1. Genes Dev. 12, 2131-2143. 